\title{
EFEITO DE EXTRATO BRUTO E ÓLEO ESSENCIAL DE ACHILLEA MILLEFOLIUM EM DESENVOLVIMENTO IN VITRO DE CORYNESPORA CASSIICOLA E PROTEÇÃO DE PEPINO À MANCHA DE CORINESPORA
}

\author{
M.M.Carlos ${ }^{1}$, K.R.F. Schwan-Estrada ${ }^{1 *}$, A.T. Itako ${ }^{1}$, \\ S.M. Bonaldo ${ }^{2}$, R.M. Mesquini ${ }^{1}$, J.B.Carvalho ${ }^{1}$, J.R. Stangarlin ${ }^{3 *}$
}

${ }^{1}$ Universidade Estadual de Maringá, Departamento de Agronomia, Av. Colombo, 5790 - Bloco I 45, CEP 87020900, Maringá, PR, Brasil. E-mail:schwan@wnet.com.br

\section{RESUMO}

\begin{abstract}
Medidas de controle de doenças por meio do uso de extratos e óleos essenciais vêm sendo investigadas como alternativa aos fungicidas convencionais. Este trabalho objetivou estudar o efeito antimicrobiano de extratos brutos aquosos e óleo essencial de Achillea millefolium no crescimento micelial (CM), na esporulação e na germinação de conídios de Corynespora cassiicola bem como a atividade de peroxidase em plantas de pepino. Para isto, o extrato bruto aquoso (EBA) $(1 ; 5 ; 10 ; 20$ e 25\%) foi incorporado ao meio de cultura BDA (batata-dextrose-ágar) e o óleo essencial (OE) (20, 40, 60, 100 e $200 \mathrm{~mL}$ ) foi distribuído sobre a superfície do meio de cultura. Disco de micélio foi repicado para os diferentes meios e o crescimento micelial avaliado, diariamente, por 7 dias. Para os ensaios in vivo, plantas de pepino foram pulverizadas com EBAs nas concentrações 1, 10 e $25 \%$, Saccharomyces cereviseae $20 \%$ e água, aos quatro e dois dias antes e concomitantemente à inoculação com C. cassiicola. Foi avaliada a severidade da doença e a atividade da enzima peroxidase. Para EBA, não houve inibição do crescimento micelial, da germinação e da esporulação em todas as concentrações testadas. Entretanto, nos tratamentos com OE, houve inibição de até $63 \%$ do crescimento micelial. Na esporulação e germinação, a inibição foi de $100 \%$ e $98 \%$, respectivamente, na alíquota de $200 \mu \mathrm{L}$ para OE. No controle da doença, o tratamento mais efetivo foi EBA a $25 \%$ quando realizado concomitante à inoculação. No intervalo de tempo avaliado, não se constatou atividade da enzima peroxidase.
\end{abstract}

PALAVRAS-CHAVE: Controle alternativo, mil-folhas, Cucumis sativus, extrato bruto aquoso, óleo essencial.

\section{ABSTRACT}

EFFECT OF CRUDE EXTRACT AND ESSENTIAL OIL OF ACHILLEA MILLEFOLIUM L. ON THE IN VITRO DEVELOPMENT OF CORYNESPORA CASSIICOLA AND PROTECTION OF CUCUMBER AGAINST CORINESPORA LEAF SPOT. The control of diseases by using crude extracts (CE) and essential oils (EO) are being investigated as an alternative to conventional fungicides. The objective of this work was to evaluate the antimicrobial effect of aqueous extracts and essential oil of Achillea millefolium on mycelial growth, sporolution and spores germination of Corynespora cassiicola, as well as peroxidase activity in cucumber plants. For this, crude extract $(1 ; 5 ; 10 ; 20$ and $25 \%)$ was incorporated into potato dextrose agar medium (PDA), and essential oil $(20,40,60,100$ and $200 \mathrm{~mL})$ was distributed over the surface of the PDA. The mycelial growth was measured daily for 7 days. In the in vivo test, cucumber plants were sprayed with crude extracts at concentrations 1; 10 and 25\%, and Saccharomyces cereviseae 20\% (control), 4 and 2 days before and the same time as inoculation with C. cassiicola. The severity of disease and peroxidase activity were evaluated. For crude extract, neither mycelial growth nor spore germination and sporulation was inhibited at any of the tested concentrations. In the treatments with essential oil there was inhibition up to $63 \%$ of the mycelial growth. In the sporulation and spores germination the inhibition was $100 \%$ and $98 \%$, respectively, for 200 uL of EO. In the control of the disease the most

${ }^{2}$ Universidade Federal de Mato Grosso, Cuiabá, MT, Brasil.

${ }^{3}$ Universidade Estadual do Oeste do Paraná, Marechal Cândido Rondon, PR, Brasil.

*Bolsista Produtividade CNPq. 
effective treatment was the crude extract $25 \%$ when carried out at the same time as the inoculation. In the evaluated period, no peroxidase activity was found.

KEY WORDS: Alternative control, yarrow, Cucumis sativus, crude extracts, essential oil.

\section{INTRODUÇÃO}

Corynespora cassiicola (Bert. \& Curt.) Wei é um patógeno com inúmeros hospedeiros, com sintomas que se caracterizam por manchas foliares, cujas formas e coloração variam de acordo com o hospedeiro encontrado (DUARTE et al., 1978). No Brasil, a doença foi constatada sobre caupi, mamão, seringueira, cacaueiro, acerola, soja, entre outros (AlmEIDA; YAMASHITA, 1978; DuARTE et al., 1978; GENEROSO et al., 2002). Em pepino, foi relatado, pela primeira vez, em 2002, em pepinos do tipo "Hishi Nari", procedentes deIndaiatuba, SP, equeapresentavam características comolesões foliares necróticas, com os bordos pardoescuros e diâmetro de cerca de cinco milímetros (VERZIGNASSI et al., 2003).

VERZIGNASSI et al. (2003) observaram que os primeiros sintomas da doença surgem inicialmente sob a forma de pequenas manchas, tipo "flecks", de tonalidade clara, que evoluem para manchas angulares, com o centro de cor palha e pequeno halo amarelo claro. Posteriormente, as manchas crescem, tomando formato arredondado e apresentando centro marrom claro e bordos encharcados de coloração olivácea.

Cultivos sucessivos de pepino "japonês", na região norte do Estado do Paraná, em estufas plásticas, tipo túnel alto, tornaram C. cassiicola um dos mais importantes patógenos nessa modalidade de cultivo, causando perdas de até 60\% (VERZIGNASsI et al., 2003; VIDA et al., 2004). A mancha de corinespora tem ocorrido com intensidade nos períodos de primavera e verão, atingindo níveis epidêmicos dentro de poucos dias após a visualização dos primeiros sintomas nas plantas. Os fungicidas utilizados para o controle de outras manchas foliares em curcubitáceas não têm apresentado resultados práticos no controle dessa doença, e os híbridos utilizados na região têm apresentado alta suscetibilidade à mancha de corinespora. Outras práticas de manejo, como eliminação de restos culturais, maior espaçamento entre plantas e manejo de cortinas laterais das estufas, não têm reduzido a severidade da doença (VERZIGNASSI et al., 2003).

Assim faz-senecessário o estudo denovas alternativas para o controle deste fitopatógeno, tais como o controle biológico e a indução de resistência. Trabalhos desenvolvidos explorando a atividade biológica de extrato bruto ou óleos essenciais de plantas medicinais têm indicado potencial no controle de fitopatógenos, por meio da indução de mecanismos de defesa nas plantas ou pela inibição do crescimento micelial e da germinação deesporos (STANGARLIN et al., 1999; SCHWAN-Estrada et al., 2008). O presente trabalho foi desenvolvido com o objetivo de estudar a ação antimicrobiana de extrato bruto aquoso e óleo essencial da planta medicinal Achillea millefolium (milfolhas) no desenvolvimento in vitro de C. cassiicola e verificar o seu efeito na proteção de C. cassiicola em plantas de pepino "japonês".

\section{MATERIALEMÉTODOS}

O isolado de Corynespora cassiicola foi cedido pelo Laboratório de Fitopatologia (UEM) e mantido em meio decultura BDA (batata-dextrose-ágar) a $25 \pm 2^{\circ} \mathrm{C}$, com fotoperíodo de 12 horas.

\section{Obtenção do extrato bruto aquoso (EBA) e óleo essencial (OE) de Achillea millefolium}

Para a obtenção do extrato aquoso, folhas frescas de A. millefolium foram coletadas, pesadas e trituradas com caldo de batata em liquidificador de maneira a se obter as concentrações de 1\%,5\%,10\%,20\% e 25\% (p:v). Em seguida foi acrescentada a dextrose éar. Os meios foram autoclavados a $120^{\circ} \mathrm{C}$ por $20 \mathrm{~min}$. $\mathrm{O}$ óleo essencial foi obtido por hidrodestilação (arraste a vapor), sendo utilizados, em média, 2,5 kg de material vegetal (folhas e hastes frescas) (CosTA, 1986).

Efeito in vitro do extrato bruto aquoso e do óleo essencial sobre $C$. cassiicola

O EBA e o OE de A. millefolium foram avaliados sobre o crescimento micelial, a esporulação e a germinação de conídios de C. cassiicola. Para testar o efeito dos extratossobreocrescimentomicelialdeC.cassiicola, após a solidificação do meio de cultura contendo os EBAs (como descrito anteriormente), um disco de 8 mm de diâmetro da colônia, foi repicado para o centro de cada placa de Petri. No ensaio, para os OEs, após esterilização do OE por filtração em membrana Millipore, alíquotas de 20, 40, 60, 100 e $200 \mu \mathrm{L}$ foram distribuídas na superfície de meio de cultura BDA, com alça de Drigalski. Após $2 \mathrm{~h}$, um disco de $8 \mathrm{~mm}$ de diâmetro, de uma colônia de C. cassiicola foi transferido para o centro de cada placa. A testemunha consistiu de placas contendo somente o meio BDA para os dois ensaios. As placas foram incubadas no escuro a $28^{\circ} \mathrm{C}$. As avaliações foram realizadas por meio da 
mensuração diária do diâmetro da colônia, correspondente à média de duas medidas diametralmente opostas da colônia fúngica, iniciando-se 24 horas após o início do trabalho e estendendo-se até quando as colônias do tratamento controle se desenvolveram até $2 / 3$ da superfície total do meio de cultura da placa. Utilizou-se o delineamento experimental inteiramente casualizado (DIC) com cinco repetições para o EBA, nas concentrações de 1,5,10,20 e 25\%, e DIC com cinco repetições para OE nas alíquotas de 20,40, 60, 100 e $200 \mu \mathrm{L}$ além de cinco repetições da testemunha absoluta, sem EBA ou OE.

A esporulação foi determinada pela contagem total de esporos das colônias do experimento anterior, logo após o término da última mensuração. Em cada placa adicionou-se $10 \mathrm{~mL}$ de água destilada estéril e a colônia foi suavemente raspada com uma alça bacteriológica. A suspensão obtida foi filtrada em gaze e os esporos contados em câmara de Neubauer. O número de esporos produzido foi expresso em número de conídios por $\mathrm{cm}^{2}$ de colônia.

No ensaio de germinação de esporos, alíquota de $80 \mu \mathrm{L}$ da suspensão de esporos $\left(1,0 \times 10^{4}\right.$ conídios. $\left.\mathrm{mL}^{-1}\right)$, provenientes das placas do experimento anterior, foram colocadas em pocinhos de placa utilizada em teste de ELISA (REGENTE et al., 1997). A placa foi incubada sob luz constante à temperatura de $25^{\circ} \pm 2^{\circ} \mathrm{C}$ por um período de $3 \mathrm{~h}$, quando a germinação foi paralisada com $10 \mu \mathrm{L}$ do corante azul de algodão. A avaliação foi realizada pela contagem de 100 esporos por pocinho, sendo considerados germinados quando apresentaram qualquer emissão de tubo germinativo. Utilizou-se o DIC com quatro repetições para o EBA nas concentrações de 1, 5, 10, 20 e 25\%, e DIC com quatro repetições de OE nas alíquotas de 20, 40, 60, 100 e $200 \mu \mathrm{L}$ além de quatro repetições da testemunha absoluta, EBA ou OE. Os resultados obtidos foram submetidos à análise de variância pelo teste $\mathrm{F}$, e a diferença entre as médias, quando significativa, foi comparada pelo teste de Skott-Knott ao nível de 5\% de probabilidade, utilizando o programa SISVAR (FERREIRA, 2000).

Controle in vivo de mancha de corinespora em pepino "japonês"

Sementes de pepino "japonês" cv. Tsuyataru foram semeadas em bandejas de isopor contendo substrato comercial e mantidas em casa-de-vegetação. A primeira folha verdadeira (15 dias de idade da planta) recebeu, por meio de aspersão com o auxílio de atomizador manual, EBA de $A$. millefolium, não autoclavado, nas concentrações de 1,10 e $25 \%$, S. cereviseae a $20 \%$ e água (testemunha absoluta). As pulverizações foram realizadas 2 e 4 dias antes ou concomitantemente à inoculação com suspensão de conídios de C. cassiicola $\left(5,2 \times 10^{4}\right.$ conídios. $\left.\mathrm{mL}^{-1}\right)$. As plantas foram mantidas em câmara úmida por 48 horas. Utilizou-se o DIC, com quatro repetições, sendo cada repetição composta por três plantas, cinco tratamentos (testemunha absoluta, $S$. cereviseae e EA de A. millefolium a 1, 10 e $25 \%$ ) aplicados aos quatro dias, dois dias e zero horas (imediatamente) à inoculação com o patógeno. Foi avaliada a área foliar lesionada (conforme escala de notas, adaptada de CAMPBELL; MADDEN, 1990), após o surgimento das primeiras lesões na testemunha absoluta (água).

\section{Análise bioquímica (peroxidase de guaiacol) (E.C.1.11.1.7)}

As coletas das amostras de tecido das plantas foram realizadas imediatamente antes da inoculação (tempo A) e sete dias após a inoculação (tempo B) com C. cassiicola. Foram utilizados três tempos de aplicação dos tratamentos: quatro dias, dois dias e zero horas (imediatamente) à inoculação com o patógeno. Foram quatro repetições por tratamento, onde cada repetição consistiu de três plantas que correspondiam ao número de amostras coletadas para avaliar a atividade enzimática da peroxidase. $\mathrm{O}$ tratamento e a inoculação foram feitos nos primeiros pares de folhas verdadeiras.

Amostras de tecido vegetal, da segunda folha verdadeira, de plantas de pepino em cada tratamento foram coletadas. Omaterial foi maceradoem almofariz e a extração da enzima foi realizada por meio da adição de $2 \mathrm{~mL}$ de tampão fosfato $0,01 \mathrm{M}(\mathrm{pH} 6,0)$ a $4^{\circ} \mathrm{C}$ e o extrato centrifugado a $6.700 \mathrm{~g}$, por $10 \mathrm{~min}$. $\mathrm{O}$ sobrenadante obtido foi armazenado a $4^{\circ} \mathrm{C}$ para determinação da atividade enzimática e do teor de proteínas totais presentes nas amostras. Em uma cubeta de vidro, com capacidade de $3 \mathrm{~mL}$, foram adicionados 2,9 mL de tampão de reação [306 $\mu \mathrm{L}$ de peróxidodehidrogênio, 12,5 mLdeguaiacole $86,5 \mathrm{~mL}$ de tampão de fosfato $0,01 \mathrm{M}(\mathrm{pH} 6,0)]$ a $0,1 \mathrm{~mL}$ do extrato proteico (sobrenadante). A reação foi conduzida durante $5 \mathrm{~min}$, com as leituras de absorbância tomadas a cada $20 \mathrm{~s}$, iniciando-se logo após a adição do extrato ao substrato. A atividade das peroxidases foi determinada a $30^{\circ} \mathrm{C}$ por meio de métodoespectrofotométrico direto(HAMMERSCHMIDT et al.,1982) a $470 \mathrm{~nm}$. A quantificação de proteínas totais presentes no extrato enzimático foi determinada utilizando-se o método proposto por BRADFORD (1976). Os valores foram expressos em Unidades de Absorbância (UA) a $470 \mathrm{~nm} / \mathrm{min} / \mu \mathrm{g}$ proteína (U.A./min $/ \mathrm{mg}$ de proteína), para atividade específica, ou Unidades de Absorbância a U.A./min/grama peso fresco (g.p.f.), para a atividade geral. 


\section{RESULTADOSEDISCUSSÃO}

Efeito in vitro do extrato bruto aquoso e do óleo essencial sobre $C$. cassiicola

Naavaliaçãodas cinco concentrações doextratode A. millefolium (Tabela 1), sobreocrescimentomicelialde C. cassiicola, observou-se nas concentrações de 10,20 e $25 \%$ que o crescimento micelial foi maior e significativamente diferente da testemunha. Nas demaisconcentrações de extrato bruto aquoso de 1 e $50 \%$ não houve diferenças significativas, em relação à testemunha. Os resultados desse trabalho demonstram que houveum estímulo no crescimento micelial do patógeno pelo extrato bruto aquoso da A. millefolium. Atribue-se isto ao fato das moléculas dos compostos antimicrobianos deste extrato (como o azuleno) terem sido inativadas pela elevação da temperatura durante o processo de autoclavagem, assim comoa maior oferta denutrientes no meio de cultura pode ter propiciado crescimento maior dopatógenonas placas com os tratamentos com os EBAs. FIoRI et al. (2000) observaram que concentrações de 20 e $25 \%$ dos EBAs de $A$. millefolium poderiam ter se constituído em substrato, estimulando o crescimento do patógeno Dydimella bryoniae. Essa baixa atividade antimicrobiana do extrato bruto de $A$. millefolium está de acordo com os resultados observados por Uskin et al. (1996), que relataram ausência da atividade dessa espécie quando usada como extrato aquoso de raízes frente a Fusarium oxysporum, Verticilium dahliae, Rhizoctonia solani, Pythium ultimum, Phytophthora megasperma e Streptomyces scabies.

Em relaçãoà esporulaçãoe germinaçãodeconídios dos tratamentos com EBA (Tabela 1), verificou-se que as concentrações testadas não apresentaram diferençasestatísticas em relaçãoà testemunha sendo queelas estimularam estes eventos. Entretanto, OGBEBOR; ADEKUNLE (2005) observaram redução no crescimento micelial e na germinação de conídios de C. cassiicola, isoladodeseringueira, quandona presença de concentrações de extrato bruto $(10,25,50$ e 100\%) de Ocimum basilicum (manjericão). Também observaram que outras plantas medicinais como Ageratum conyzoides (mentrasto), Allium sativum (alho) e Portulaca oleraceae (beldroega), entre outras, não apresentaram efeito inibitório sobre o fungo C. cassiicola. Já em relação ao OE, em todas as alíquotas utilizadas, houve redução no crescimento micelial de C. cassiicola (Tabela 2), estatisticamente diferente da testemunha sendo que a maior inibição foi na presença de $200 \mu \mathrm{L}$ do óleo essencial.

Tabela 1 - Efeito do extrato bruto aquoso (EBA) de Achillea millefolium na esporulação e na germinação de conídios de Corynespora cassiicola de pepino.

\begin{tabular}{lccccc}
\hline Tratamento & Esporulação $/ \mathrm{cm}^{2}$ & Germinação \% & Inibição \% & $\begin{array}{c}\text { Crescimento } \\
\text { micelial } / \mathrm{cm}\end{array}$ & $\begin{array}{c}\text { Crescimento } \\
\text { médio/cm }\end{array}$ \\
\hline EB 1\% & $60,33 \mathrm{a}$ & $93,25 \mathrm{a}$ & 0 & $5,54 \mathrm{a}$ & $6,52 \mathrm{a}$ \\
EB 5\% & $61,00 \mathrm{a}$ & $89,75 \mathrm{a}$ & 0 & $5,72 \mathrm{a}$ & $6,82 \mathrm{a}$ \\
EB 10\% & $41,66 \mathrm{a}$ & $75,50 \mathrm{~b}$ & 0 & $6,20 \mathrm{~b}$ & $7,54 \mathrm{~b}$ \\
EB 20\% & $11,33 \mathrm{~b}$ & $70,50 \mathrm{~b}$ & 0 & $6,52 \mathrm{~b}$ & $8,01 \mathrm{~b}$ \\
EB 25\% & $47,33 \mathrm{a}$ & $97,51 \mathrm{a}$ & 0 & $6,14 \mathrm{~b}$ & $7,44 \mathrm{~b}$ \\
Testemunha & $34,00 \mathrm{a}$ & $66,25 \mathrm{~b}$ & $5,83 \mathrm{a}$ & $6,93 \mathrm{a}$ \\
CV \% & 19,87 & 19,45 & 5,96 & 7,66
\end{tabular}

Médias nas colunas seguidas pela mesma letra não diferem estatisticamente pelo teste de Scott-Knott a 5\% de probabilidade.

Tabela 2 - Efeito de alíquotas de óleo essencial (OE) de Achillea millefolium no crescimento micelial, na esporulação e na germinação de conídios de Corynespora cassiicola de pepino.

\begin{tabular}{lccccc}
\hline Tratamento & Esporulação/ $\mathrm{cm}^{2}$ & Germinação \% & Inibição \% & $\begin{array}{c}\text { Crescimento } \\
\text { micelial } / \mathrm{cm}\end{array}$ & $\begin{array}{c}\text { Crescimento } \\
\text { médio } / \mathrm{cm}\end{array}$ \\
\hline OE 20 & $52,50 \mathrm{a}$ & $52,50 \mathrm{a}$ & 20,75 & $4,82 \mathrm{~b}$ & $0,51 \mathrm{~b}$ \\
OE 40 & $5,62 \mathrm{~b}$ & $9,02 \mathrm{~b}$ & 86,41 & $4,32 \mathrm{~b}$ & $0,42 \mathrm{~b}$ \\
OE 60 & $6,55 \mathrm{~b}$ & $7,75 \mathrm{~b}$ & 88,30 & $4,01 \mathrm{~b}$ & $0,39 \mathrm{~b}$ \\
OE 100 & $6,25 \mathrm{~b}$ & $2,25 \mathrm{~b}$ & 96,60 & $4,27 \mathrm{~b}$ & $0,44 \mathrm{~b}$ \\
OE 200 & $0,00 \mathrm{~b}$ & $1,25 \mathrm{~b}$ & 98,11 & $3,42 \mathrm{~b}$ & $0,32 \mathrm{~b}$ \\
Testemunha & $35,00 \mathrm{a}$ & $64,53 \mathrm{a}$ & & $6,44 \mathrm{a}$ & $0,70 \mathrm{a}$ \\
CV \% & 29,39 & 33,32 & 16,94 & 22,33 \\
\hline
\end{tabular}

Médias nas colunas seguidas pela mesma letra não diferem estatisticamente pelo teste de Scott-Knott a 5\% de probabilidade. 
Em relação à esporulação e germinação de conídios, na presença deOEde $A$. millefolium, apenas a alíquota de 20 mLnãodiferiu da testemunha pelotesteScott-Knotta 5\% deprobabilidade(Tabela 2). Na presença das demais alíquotas observaram-se redução tanto na esporulação quantona germinação dos conídios. Oefeito fungitóxico doóleo essencial de $A$. millefolium também foi observado por FIORI et al. (2000) em Didymella bryoniae onde, na alíquota de $100 \mathrm{~mL}$, encontraram inibição de $96 \%$ na germinação de conídios e, por microscopia eletrônica de varredura, observaram crescimento atípico e degeneraçãodashifas de D. Bryoniae. BonALDOetal.(2007) observaramqueoóleoessencialdeCorymbiacitriodora (eucalipto), em todas as alíquotas testadas $(5,10,20 ; 40$ e $60 \mu \mathrm{L})$, inibiu o crescimento micelial e a germinação de conídios de AlternariaalternataeColletotrichumsublineolumeescleródios de Sclerotium rolfsii.

Controle in vivo de mancha de corinespora em pepino "japonês"

A severidade da doença, avaliada sete dias após as inoculações nas primeiras e segundas folhas, mostrou que houve redução na área foliar lesionada (afl) em função direta do aumento nas concentrações do extrato brutoaquoso de A. millefolium (Fig.1). Os extratosaquosos brutos a $1 \%, 10 \%$ e $25 \%$ diferiram estatisticamente entre si quando utilizados no intervalo de quatro dias (T1), dois dias (T2) e (T3) antes da inoculação com o patógeno C. cassiicola. A partir da concentração de 10\%, nos $\mathrm{T} 2$ e T3, os extratos reduziram significativamente a severidadenas folhas quehaviam recebidodiretamente esses extratos apresentando efeito local. No tempo de aplicação T1, as áreas lesionadas foram intensas, apresentandoas maiores médiasnessetratamento. Os trata- mentos EBA 1\%, no T3, EBA 10\%, no T1 e o tratamento testemunha positiva também não diferiram estatisticamente, apresentando valores de severidade da doença deaté $6 \%$ deafl. Mas os tratamentos EBA $1 \%$,no T1 eno T2, e o tratamento S. cereviseae, no T1 eno T2, apresentaramas maiores médias deáreas foliares lesionadas (afl). Emalgumas plantas, foram verificados sintomas dealta agressividade, incluindo seca do limbo foliar e lesões cotiledonares. Folhas tratadas com EBA a 1\% apresentaramlesõesintensas deC.cassiicola esemelhantes entre si, nos dois primeiros tempos de aplicação do tratamentoindutor(T1eT2). Estatisticamente, observou-sequeas médias entre os tratamentos com S. cereviseae e EBA $1 \%$ foram similares entre os tempos de aplicação dos tratamentos (T1 e T2). Os tratamentos EBA a 25\% aplicados a quatro (T1) e dois (T2) dias antes da inoculação, $S$. cereviseae a quatro dias(T1)eEBA $10 \%$ a dois(T2)ezero dias (T3) antes da inoculação, não diferiram estatisticamente entre si, apresentando severidade menores 3\% (afl). A menor área lesionada foi encontrada no tratamento com EBA 25\%, destacando-se o T3 de aplicação, ondefoi constatada ainexistência delesões. Esse, ainda, não diferiu estatisticamente do tratamento testemunha absoluta (sem inoculação), apresentando um controle muito próximoa um controle total. Nos tempos T2eT1, foi verificada a presença de poucos "fleks" (pontuações cloróticas). Embora os tratamentos EBA 25\%,nos intervalosdeT1eT2, tenham diferidodoEBA25\%,noT3eles mostraram-se promissores para o controle da doença, pois a presentaram valores inferiores a $1 \%$, como relatado anteriormente, possivelmente, pelo efeito direto do extrato bruto aquoso de $A$. millefolium nas plantas de pepino. Aindução de resistência nãopodeser descarta$\mathrm{da}$, pois os mecanismos de defesa podem ser rapidamenteativados.

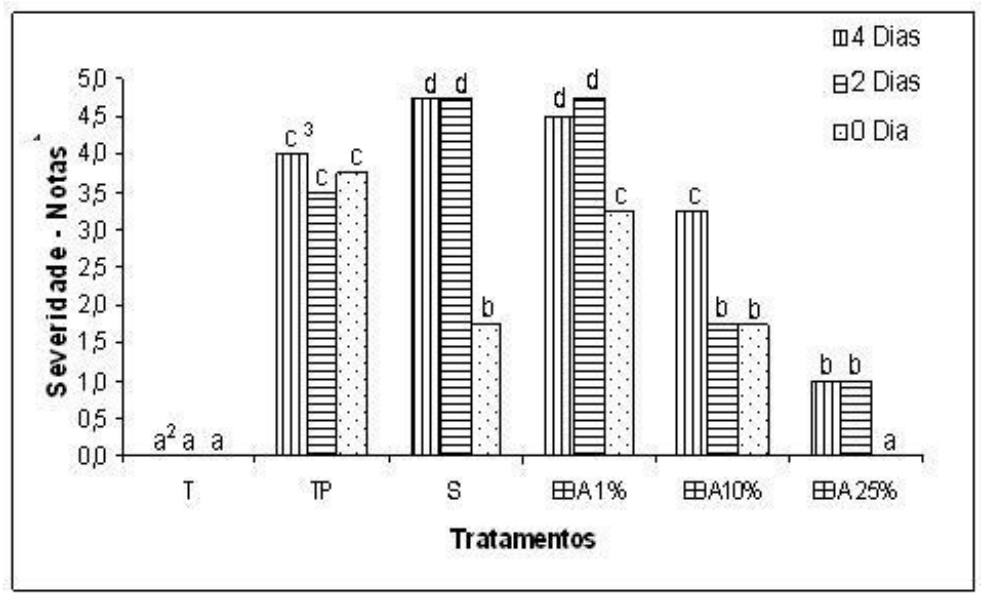

Fig. 1 - Severidade de mancha-alvo (Corynespora cassiicola) em plantas de pepino, sete dias após a inoculação. Plantas tratadas com extrato bruto aquoso (EBA) de Achillea millefolium aos quatro dias, dois dias e zero dias antes da inoculação. ${ }^{1}$ Escala de notas: $0=$ ausência de sintomas; $1=<1 \%$ de área foliar lesionada (afl); $2=1 \%$ a 3\% de afl; $3=3,1 \%$ a $6 \%$ de afl; $4=6,1 \%$ a $12 \%$ de afl; $5=12,1 \%$ de afl. ${ }^{2}$ Médias seguidas de mesma letra não diferem entre si pelo teste de Scott-Knott a 5\% de significância. ${ }^{3} \mathrm{~T}$ - Testemunha Absoluta; TP- Testemunha Positiva (água+ fitopatógeno); S- Saccharomyces cereviseae; EBA - Extratos Brutos Aquosos a 1\%, 10\% e 25\%. 

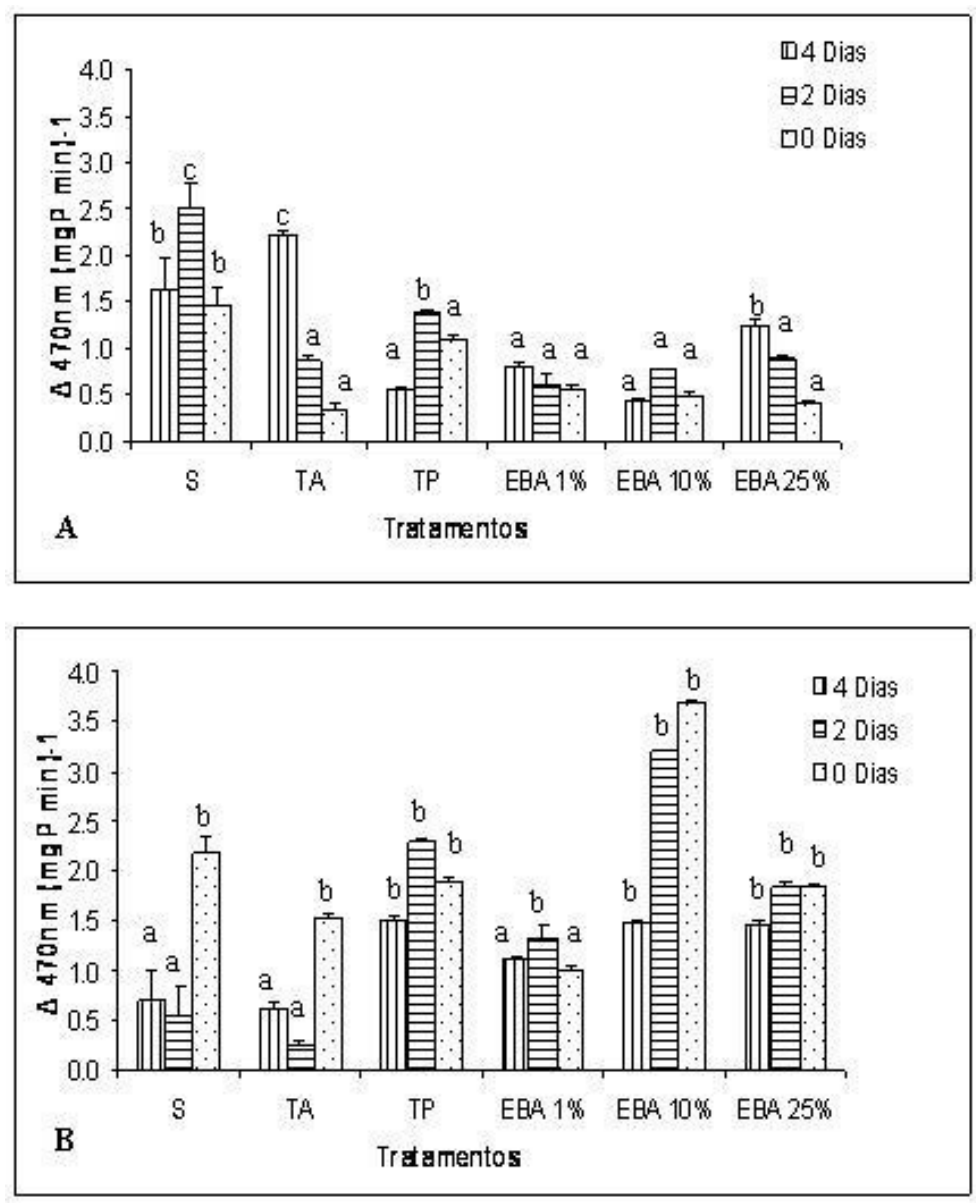

Fig. 2 - Atividade específica de peroxidase em plantas de pepino na segunda folha verdadeira tratadas aos quatro dias, dois dias antes (A), após (B) e concomitantemente com a inoculação de Corynespora cassiicola (A). As barras representam o desvio padrão da média $( \pm)$ de quatro repetições. TA- Testemunha Absoluta; TP- Testemunha Positiva (água + fitopatógeno); S- Saccharomyces cereviseae (controle); EBA- Extrato Bruto Aquoso a 1, 10 e 25\%. Médias seguidas de mesma letra não diferem entre si pelo teste de Scott-Knott a 5\% de significância.

Entre os tratamentos 1, 10 e 25\% de EBA, ficaram evidentes as relações inversas de quantidade de lesões, de acordo com o aumento da concentração do extrato bruto aquoso aplicado. Ofato de o tratamento mais efetivo e mais direto ter sido o EBA $25 \%$ pode indicar um efeito de dose dependente das concentrações de EBA. A redução da área foliar lesionada pode constituir-se em um dos principais efeitos da resistência induzida (Bell, 1981, citado por StANGARLIN; Pascholati, 1994).

A atividade deperoxidase, de um modo geral, não pode ser correlacionada com a área foliar lesionada, em nenhum dos tratamentos aplicados (Fig. 2). Possivelmente a atividade desta enzima é detectada nas primeiras horas após a aplicação dos eliciadores e, neste caso, como as dosagens foram realizadas a partir de $48 \mathrm{~h}$ não se pode detectar a ativação enzimática. Entretanto, pode-se observar que após a inoculação houve incremento na atividade de peroxidase principalmente em plantas tratadas com EBA $10 \%$ aos $2 \mathrm{e} 0$ dias, embora não se tenha observa- dodiferenças significativas. Quando comparado com a testemunha positiva (água + fitopatógeno) observase incrementos de aproximadamente 25 e $42 \%$ na atividade da enzima, aos 2 ezero dias, respectivamente em plantas tratadas com EBA $10 \%$.

Pereira et al. (2008) avaliaram a eficiência de extratos de casca de café, óleo essencial de tomilho e acibenzolar-S-metil(ASM) nomanejo decercosporiose em cafeeiro e observaram picos de atividade da peroxidase aos $2 \mathrm{e} 11 ; 7 \mathrm{e} 11 \mathrm{e} 2 \mathrm{e} 9$ dias após a aplicação dos tratamentos, respectivamente. Já em folhas de tomateiro, as análises bioquímicas realizadas mostraram que as peroxidases não são bons marcadores de resistência, pois nãohouve diferenças noacúmulo dessas enzimas entre plantas tratadas com ASM (acibenzolar-S-metil), indutor de resistência altamenteeficiente sobreo controle da bacteriose Xanthomonas vesicatoria (Di Piero; Pascholati, 2004). De acordo com SCHNEIDER; UlLRICH (1994), alguns indutores de resistência em pepino não elevam o nível de peroxidases na magnitude da proteção induzida, a exemplo do 
que ocorreu em plantas tratadas com extratos de Reynoutria sachalinensis. No trabalho de Di PIERO; Pascholati (2004) constatou-se que vários indutores bióticos e abióticos elevaram as atividades das peroxidases como também de quitinases e $\beta-1,3-$ glucanases, em plantas de pepino, mas sem haver relação entre o aumento da atividade de uma enzima em particular e a indução de resistência, o que reforça a hipótese de que a resistência é um processo multicomponente. Rотн et al. (2000) demonstraram que a aplicação de extrato aquoso de Lychnis viscaria em plantas de pepino induziu aumento da atividade de até $20 \%$ da peroxidase, $30 \%$ de quitinase e $68 \%$ de $\beta$-1,3-glucanase, concluindo que o extrato da planta induz mecanismos bioquímicos de resistência. No presente artigo, a ausência da atividade de peroxidases pode ter sido em função do intervalo do tempo deavaliação(2e 4 dias). Estudos futuros devem ser conduzidos utilizando-se diferentes tempos de amostragens (coleta) edosagens da enzima peroxidase em intervalos menores de tempo (a partir de 6h, por exemplo).

\section{CONCLUSÕES}

O óleo essencial de $A$. millefolium apresenta efeito inibitório, in vitro, principalmente na esporulação de C. cassiicola e o extrato aquoso, a $25 \%$, controla a doença sugerindo a utilização desta planta como possível fungicida natural para o controle deste fitopatógeno em pepino. Porém, estudos ainda devem ser conduzidos para verificar o potencial indutor destes subprodutos de A. millefolium.

\section{REFERÊNCIAS}

ALMEIDA, A.M.R.; YAMASHITA, J. Efeito da técnica de inoculação de Corynespora cassiicola (Bert. \& Curt.) Wei na reação de três cultivares de soja. Fitopatologia Brasileira, v.3, p.55-58, 1978.

BONALDO, S.M; SCHWAN-ESTRADA, K.R.F.; STANGARLIN, J.R.; CRUZ, M.E.S.; FIORI-TUTIDA, A.C.G. Contribuição ao estudo das atividades antifúngica e elicitora de fitoalexinas em sorgo e soja por eucalipto (Eucalyptus citriodora). Summa Phytopathologica, v.33, p.383-387, 2007.

BELL, A.A. Biochemical mechanisms of disease resistance. Annual Review of Plant Physiology, v.32, p.2183, 1981.

BRADFORD, M.M. A rapid and sensitive method for the quantitation of microgram quantities of protein utilizing the principle of protein- dye binding. Analytical Biochemistry, v.72, p.248-254, 1976.
CAMPBELL, C.L.; MADDEN, L. Introduction to plant disease epidemiology. New York: Wiley, 1990. 532p.

COSTA, A.F. Farmacognosia. Lisboa: Fundação Calouste Gulbenkian, 1986. v.1, 1031p.

DI PIERO, R.M.; PASCHOLATI, S.F. Indução de resistência em plantas de pepino contra Colletotrichum lagenarium pela aplicação de extratos de basidiocarpos de Lentinula edodes e de Agaricus blazei. Summa Phytopathologica, v.30, n.2, p.243-250, 2004.

DUARTE, M.L.R.; ALBUQUERQUE, F.C., PRABHU, A.S. Uma nova enfermidade foliar do cacaueiro (Theobroma cacau L.) causada pelo fungo Corynespora cassiicola (Bert. \& Curt) Wei. Fitopatologia Brasileira, v.3, p.259-265,1978.

FERREIRA, D.F. Manual do sistema Sisvar para análises estatísticas. Lavras: Universidade Federal de Lavras, 2000. 66p.

FIORI, A.C.G.; SCHWAN-ESTRADA, K.R.F.; STANGARLIN, J.R.; VIDA, J.B.; SCAPIM, C.A.; CRUZ, M.E.S.; PASCHOLATI, S.F. Antifungal activity of leaf extrats and essential oils of some medicinal plants against Didymella bryoniae. Journal of Phytopathology, v.148, p.483-487, 2000.

GENEROSO, E.C.S.; KONRAD, M.; HERNANDEZ, F.B.T.; PAPA, M.F.S. Ocorrência de fungos patogênicos na aceroleira irrigada, no município de Junqueirópolis, SP. In: CONGRESSO BRASILEIRODE ENGENHARIA AGRÍCOLA - CONBEA, 31., 2002, Salvador. Resumos. 1 CD ROM.

HAMMERSCHMIDT, R.; NUCKLES, E.; KUÆ, J. Association of enhance peroxidase activity with induced systemic resistance of cucumber to Colletotrichum lagenarium. Physiological and Molecular Plant Pathology, v.20, p.73-82, 1982.

OGBEBOR, N.; ADEKUNLE, A.T. Inhibition of conidial germination and mycelial growth of Corynespora cassiicola (Berk and Curt) of rubber (Hevea brasiliensis muell. Arg) using extracts of some plants. African Journal of Biotechnology, v.4, p.996-1000, 2005.

PEREIRA, R.B.; ALVES, E.; RIBEIRO JUNIOR, P.M., RESENDE, M.L.V.; LUCAS, G.C.; FERREIRA, J.B. Extrato de casca de café, óleo essencial de tomilho e acibenzolar-S-metil no manejo da cercosporiose-docafeeiro. Pesquisa Agropecuária Brasileira, v.43, n.10, p.1287-1296, 2008.

REGENTE, M.C.; OLIVA, C.R.; FFELDMAN, M.L.; CASTAGNARO, A.P.; CANAL, L. A sunflower leaf antifungal peptide active against Sclerotinia sclerotiorum. Physiologia Plantarum, v.100, n.1, p.178-182, 1997.

ROTH, U., FRIEBE, A., SCHNABL, H. Resistance induction in plants by a brassinosteroid-containing extract of Lychnis viscaria L. Journal of Biosciences, v.55, n.7, p.365-367, 2000. 
SCHNEIDER, S.; ULLRICH, W.R. Differential induction of resistance and enhanced enzyme activities in cucumber and tobacco caused by treatment with various abiotic and biotic inducers. Physiological and molecular Plant Pathology, v.45, p.291-304, 1994.

SCHWAN-ESTRADA, K.R.F; FIORI-SUZUKI, C.C.L.; ITAKO, A.T. Utilização de extratos vegetais no controle de doenças de plantas. In: (Ed.). Métodos alternativos de controle de insetos-praga, doenças e plantas daninhas: panorama atual e perspectivas na agricultura. Belém: Embrapa Amazônia Oriental, 2008. Cap. 6, 308p.

STANGARLIN, J.R.; PASCHOLATI, S.F. Proteção de plântulas de milho pipoca contra Exserohilum turcicum pelo uso de Saccharomyces cereviseae. Summa Phytopathologica, v.20, n.1, p.16-21, 1994.

STANGARLIN, J.R.; SCHWAN-ESTRADA, K.R.F.; CRUZ, M.E.S.; NOZAKI, M.H. Plantas medicinais e controle alternativo de fitopatógenos. Biotecnologia, Ciência e Desenvolvimento, v.11, p.16-29, 1999.
USKINI, J.; HAYAKAWA, Y.; TADANO, T. Medicinal plants for supressing soil-borne plant diseases. Screening for medicinal plants with antimicrobial activity in roots. Soil Science and Plant Nutrition, v.42, p.423-426, 1996.

VERZIGNASSI, J.R.; VIDA, J.B.; TESSMANN, D.J. Epidemias de mancha de Corinespora em pepino "tipo japonês" sob cultivo protegido na região norte do estado do Paraná. Fitopatologia Brasileira, v. 28, n.5, p.570, 2003.

VIDA, J.B.; OLIVEIRA, R.R.; TESSMANN, D.J.; VERZIGNASSI, J.R.; COSTA, H. A agricultura protegida: Plasticultura-Hortaliça-Manejo de doenças. In: (Ed.). Cultivo em ambiente protegido histórico, tecnologia e perspectivas. Viçosa: UFV, 2004. 332p. Cap. 8.

Recebido em 16/2/09

Aceito em 22/4/10 